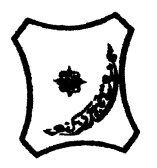

Bayero Journal of Pure and Applied Sciences, 10(1): 565 - 569

ISSN 2006 - 6996

\title{
(Olea europaea) SEEDLINGS REPLANTED IN HYDROPONIC SOLUTIONS \\ EFFECTS OF ANTHRANILIC ACID ON NICKEL ABSORPTION BY OLIVE
}

Dagari, M.S. ${ }^{1}$, Saulawa, A. A. ${ }^{2}$ and Mutawakkil, A. B. ${ }^{3}$

${ }^{1}$ Department of Chemistry, Federal University, Gashua, Nigeria

${ }^{2}$ Department of Pure and Industrial Chemistry, Bayero University, Kano, Nigeria

${ }^{3}$ Department of Chemistry, Kano University of Science and Technology, Wudil , Nigeria

Correspondence author: Tel. 08065497722, 08023714912, Email: dagaribuk@gmail.com

ABSTRACT

The effects of anthranilic acid on absorption of $\mathrm{Ni}^{2+}$ by olive (Olea europaea) seedlings treated with hydroponic solutions were investigated. Ten week old seedlings were collected from the garden of the Department of Forestry and Wild Life, Kano University of Science and Technology Wudil. Concentrations of $\mathrm{Ni}^{2+}$ in the hydroponics were varied from 0.000 to $0.025 \mathrm{moldm}^{-3}$ and anthranilic acid from 0.000 to $0.100 \mathrm{moldm}^{-3}$. The seedlings were replanted and kept in the garden of the Department of Pure and Industrial Chemistry Bayero University Kano. The weights of plants decreased significantly $(P r=0.0359<0.05)$ with increase in concentration of $\mathrm{Ni}^{2+}$ and insignificantly $(\mathrm{Pr}=0.8366>0.05)$ with increase in concentration of anthranilic acid The harvesting time varied highly significantly $(\mathrm{Pr}<0.0001)$ with concentrations of $\mathrm{Ni}^{2+}$ or anthranilic acid. The $\mathrm{pH}$ values of treated hydroponics before planting and after harvest were highly significantly $(\mathrm{Pr}<0.0001)$ lower than control $\mathrm{pH}$. Concentrations of nickel accumulated $(\mathrm{Pr}<0.0001)$ in all treated hydroponics and control. There was a significant decrease $(\mathrm{Pr}=0.0002<0.05)$ in nickel translocation factor in all plants grown in treated plants compared to control. The values were less than 1.00 which indicated increased retention of nickel in olive root with very less movement to the shoot.

Key Words: Anthranilic acid, Hydroponic, Olive, Nickel, Concentration.

INTRODUCTION

Nickel (Ni) is considered to be an essential ultra micronutrient for plant metabolism. The element is the active center of urease and cofactor of a superoxide dismutase isoform (Kupper and Kroneck 2007). Due to its very low natural occurrence in plants $(0.05-10 \mu \mathrm{g} \mathrm{g-1}$ dry weight), Ni deficiency is rare relative to the excess caused by metal mining and smelting (Nieminen et al. 2007). Excess $\mathrm{Ni}$ in plants becomes toxic in some species and in such cases alters various physiological processes. The most obvious symptoms of $\mathrm{Ni}$ toxicity in plants are growth inhibition, chlorosis, necrosis and wilting (Pandey and Sharma, 2002; Kazemi et al. 2010). Although $\mathrm{Ni}$ is not generally considered to be a redox-active metal, high concentrations of $\mathrm{Ni}$ stimulate the production of reactive oxygen species (ROS) such as $\mathrm{O}_{2} \cdot$ - and $\mathrm{H}_{2} \mathrm{O}_{2}$ (Gajewska and Sklodowska, 2007) and induce oxidative stress evident from peroxidation of membrane lipids (Baccouch et al, 2001; Kazemi et al, 2010; Wang et al, 2010). Lipid peroxidation can also be initiated by enzyme activity such as that of lipoxygenase (LOX) (Mishra and Choudhuri 1999) and is believed to be a factor affecting growth inhibition in plants exposed to heavy metals, including $\mathrm{Ni}$ (Baccouch et al, 2001).

Nickel(II) ion in the concentrations 0.0000 , 0.0025 and 0.025 moldm $^{-3}$ as $\mathrm{Ni}\left(\mathrm{NO}_{3}\right)_{2} .6 \mathrm{H}_{2} \mathrm{O}$ and $0.000,0.005, \quad 0.025$ and 0.1000 moldm $^{-}$
This research was aimed at investigating the effects of anthranilic acid on nickel absorption by olive (olea europaea) seedlings replanted in hydroponic solutions.

\section{MATERIALS AND METHODS Sampling}

Ten week old olive (Olea europaea) seedlings were collected from a garden at the Department of Forestry and Wild life, Kano University of Science and Technology, Wudil, Kano ,Nigeria. They were identified at the Department of Plant Science, Bayero University Kano

Replanting of Seedlings

The olive seedlings were uprooted from their planting bags, washed thoroughly with tap water to remove excess soil and rinsed three times with deionised water. A control hydroponic was prepared by carefully transferring $1.28 \mathrm{~cm}^{3}$ of $0.10 \mathrm{moldm}^{-3} \mathrm{KNO}_{3}$, $5.15 \mathrm{~cm}^{3}$ of $0.10 \mathrm{moldm}^{-3} \mathrm{FeCl}_{3} .6 \mathrm{H}_{2} \mathrm{O}, 11.35 \mathrm{~cm}^{3}$ of $0.10 \mathrm{moldm}^{-3} \mathrm{H}_{3} \mathrm{BO}_{3}, 5.00 \mathrm{~cm}^{3}$ of $0.05 \mathrm{moldm}^{-3}$ $\mathrm{MgSO}_{4} \cdot \mathrm{H}_{2} \mathrm{O}, 3.57 \mathrm{~cm}^{3}$ of $0.05 \mathrm{moldm}^{-3} \mathrm{Ca}\left(\mathrm{NO}_{3}\right)_{2}$ $.4 \mathrm{H}_{2} \mathrm{O}, 5.00 \mathrm{~cm}^{3}$ of $0.05 \mathrm{moldm}^{-3} \quad \mathrm{Na}_{2} \mathrm{H}_{2} \mathrm{P}_{3} \mathrm{O}_{7}$, $0.17 \mathrm{~cm}^{3}$ of $0.0075 \mathrm{moldm}^{-3} \mathrm{KI}$ and $23.10 \mathrm{~cm}^{3}$ of $0.05 \mathrm{moldm}^{-3} \quad \mathrm{MnSO}_{4} \cdot \mathrm{H}_{2} \mathrm{O}$ into a $500 \mathrm{~cm}^{3}$ volumetric flask The volume was made to mark with deionized water ( Peralta et al, 2000).

${ }^{3}$ Anthranilic acid(AA) were added to the control mixture to prepare $500 \mathrm{~cm}^{3}$ each of different hydroponic treatments in triplicates. 
The solutions were carefully transferred into clean labeled $750 \mathrm{~cm}^{3}$ table water plastic bottles. The seedlings were replanted on Wednesday 21st January, 2015 by 2.00pm (IITA, 1979 ) .

The seedlings were monitored in the garden at the Department of Pure and Industrial Chemistry, Bayero University, Kano. They were harvested separately, washed with tap water, rinsed thoroughly with deionized water and then dried in sealed plastic bags.

\section{Plant Tissue Analysis}

The various parts of the harvested seedlings were ground to fine powder. Porcelain crucibles were washed, dried and ignited on a hot electric plate for 5minutes. Based on availability, $0.25 \mathrm{~g}$ (root) and $1.00 \mathrm{~g}$ (shoot) were separately weighed into the crucibles and gently heated on the hot electric plate until the smoking ceased. They were then ashed at $450^{\circ} \mathrm{C}$ in a muffle furnace to constant weight. The ash was cooled in a desiccator, dissolved in $0.10 \mathrm{M} \mathrm{HNO}_{3}$, filtered into a $50 \mathrm{~cm}^{3}$ volumetric flask and made to mark. $\mathrm{Ni}^{+2}$ content in the roots and shoots was analyzed using Atomic Absorption Spectrophotometer at $232.0 \mathrm{~nm}$. The concentration of $\mathrm{Ni}^{+2}$ was reported as $\mathrm{mg} / \mathrm{kg}$ dry weight (IITA, 1979).

\section{Data Analysis}

The data were analyzed through one-way analysis of variance (ANOVA) using SAS (Statistics for applied sciences) software to determine the effects of various treatments. Least significant difference (LSD) tests were performed to determine the statistical significance of the differences between means of treatments at $95 \%$ probability level.

\section{RESULTS AND DISCUSSION}

Determination of Field Parameters

Change in Harvesting Time $(\Delta \mathrm{HT})$

The change in harvesting time for a given treatment is compared with the corresponding control value. A negative value shows that the plant was harvested earlier than the control plant. .Fig. 1 shows the change in harvesting time against concentration of added $\mathrm{Ni}^{2+}$.

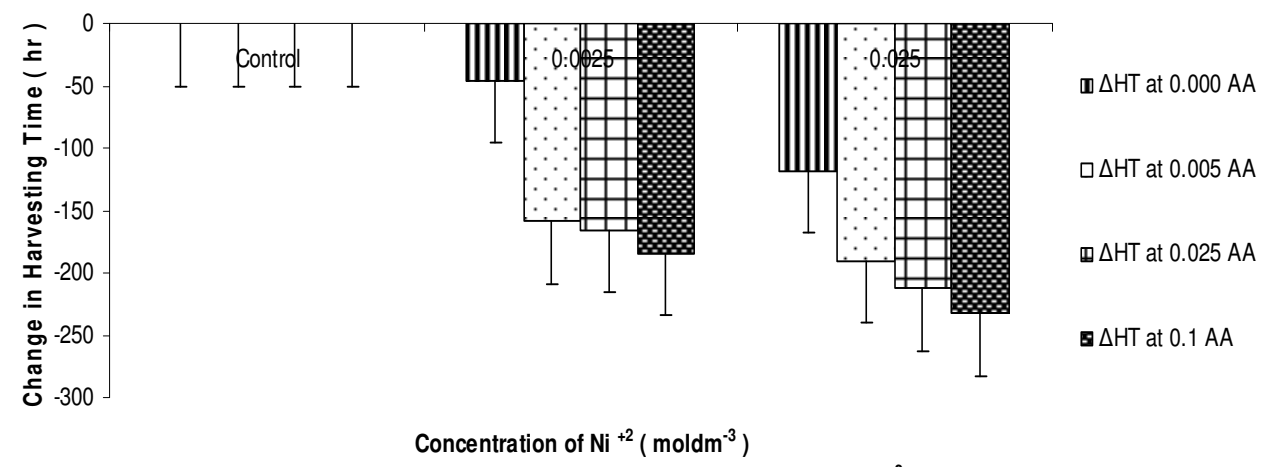

Fig.1 : Change in Harvesting Time against Concentration of $\mathrm{Ni}^{+2}$

The change in harvesting time for control plant was zero. All other treatments gave negative values for $\Delta \mathrm{HT}$. Those plants died and were harvested much earlier than control.. The change in harvesting time caused by addition of different concentrations of $\mathrm{Ni}^{2+}$ was highly significant $(\mathrm{Pr}<0.0001)$. The phytotoxic effects of $\mathrm{Ni}^{2+}$ ion might be responsible for the earlier death of the seedlings, a result consistent with the findings of Brune and Dietz (1995).

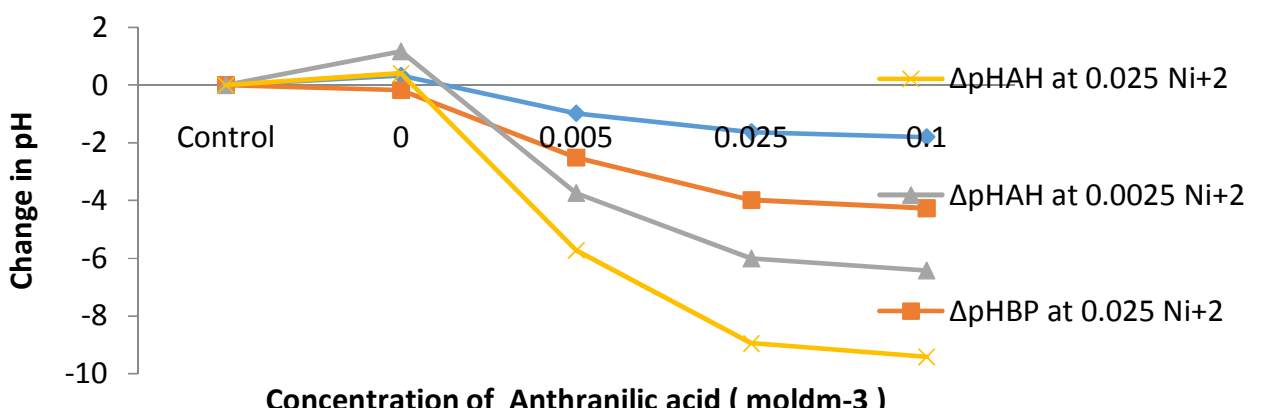

Concentration of Anthranilic acid ( moldm-3)

Fig.2: Change in pH against Concentration of Anthranilic a $A \mathrm{AHBP}^{\mathrm{HB}}$ at $0.0025 \mathrm{Ni}+2$ 
Changes in $\mathrm{pH}$ before Planting $\left(\Delta \mathrm{pH}_{\mathrm{BP}}\right)$ and after Harvest $\left(\Delta \mathrm{pH}_{\mathrm{AH}}\right)$

The changes in $\mathrm{pH}$ before planting $\left(\Delta \mathrm{pH}_{\mathrm{BP}}\right)$ and after harvest $\left(\Delta \mathrm{pH}_{\mathrm{AH}}\right)$ were determined by subtracting the $\mathrm{pH}$ of a given treatment from the $\mathrm{pH}$ of the corresponding control.

This is supported by the report of Pandey and Sharma (2002) who found that nickel toxicity on growth and metabolism of plants depended on the $\mathrm{pH}$ of the nutrient solution.
Fig. 2 shows the $\mathrm{pH}$ changes before planting and after harvest against the concentrations of anthranilic acid.

The changes in $\mathrm{pH}$ of the various hydroponic treatments which were highly significant $(\operatorname{Pr}<0.0001) \quad$ facilitated the absorption of sufficient quantities of $\mathrm{Ni}^{2+}$ to kill the growing seedlings.

Change in Plant Weight $(\Delta \mathrm{WP})$

The change in plant weight for all treatments including the control is the difference between the weight of plant before replanting and the weight of plant after harvest. A negative value of $\triangle W P$ indicates a decrease in plant weight. Fig. 3 shows the changes in plant weight with concentration of $\mathrm{Ni}^{2+}$.

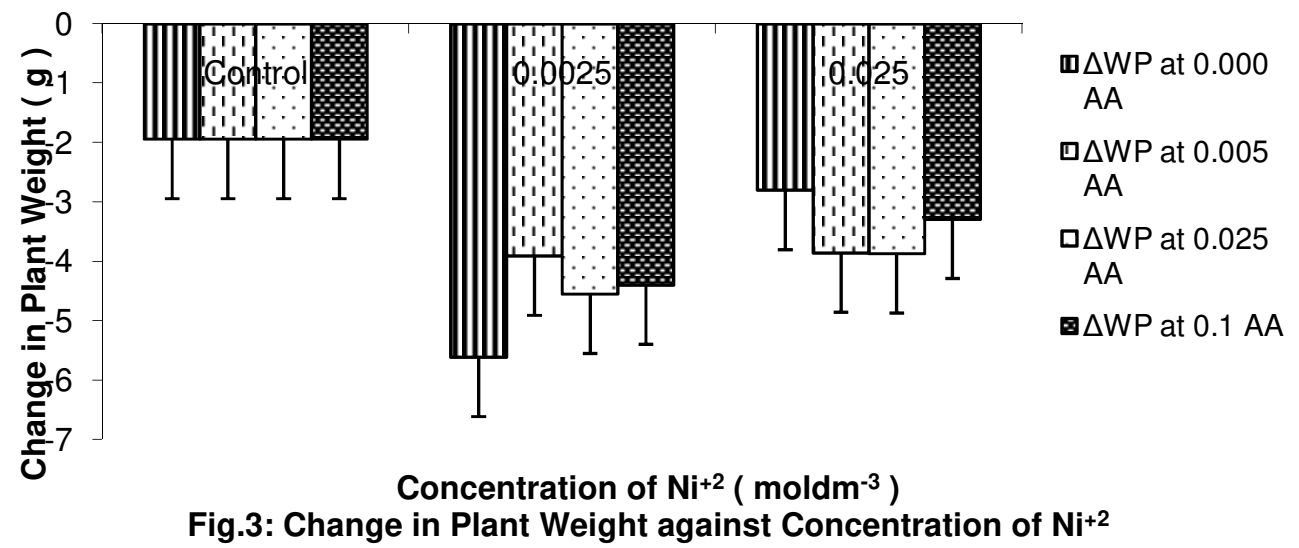

The dependence of the change in biomass of plant species on concentrations of toxic metals in nutrient solution was reported by Pandey and Sharma (2002). In this work, a significant change in plant weight $(\operatorname{Pr}=0.0359<0.05)$ was observed in all treatments including the control.

Plant Parameters

Changes in Concentrations of Root and Shoot $\mathrm{Ni}^{2+}$

Changes in concentrations of root and shoot $\mathrm{Ni}^{2+}$ accumulated in Olive seedlings growing in different hydroponic solutions are shown in Fig. 4.These changes which were highly significant $(\mathrm{Pr}<0.0001)$ were determined by subtracting the control values of $\mathrm{Ni}^{2+}$ in shoot and root from the values in various treatments.

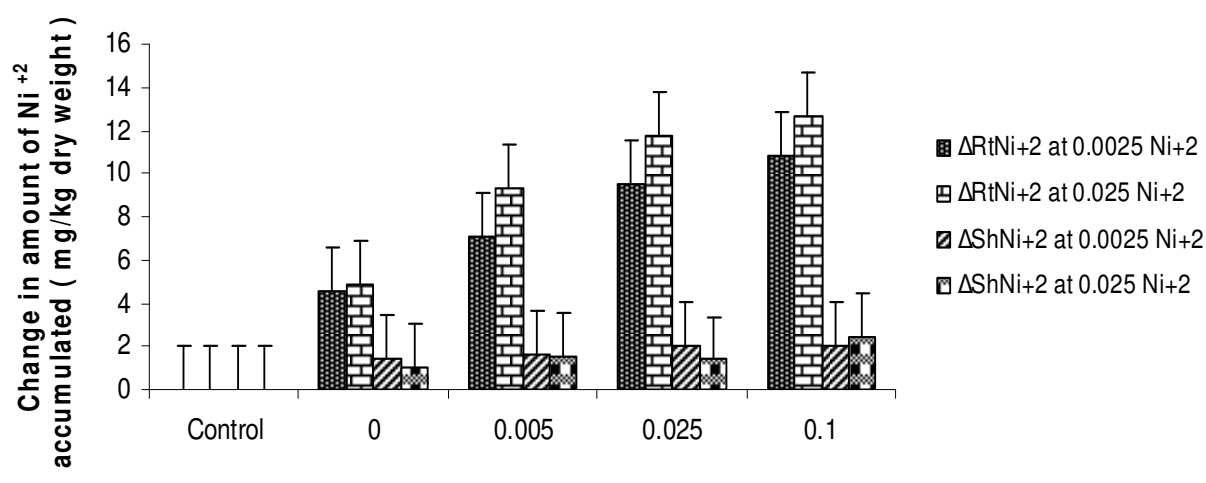

Concentration of Anthranilic acid (moldm ${ }^{-3}$ )

Fig.4: Change in amount of $\mathrm{Ni}^{+2}$ against Concentration of Anthranilic acid 
The roots are important for element uptake in plants (Sharma and Gaur, 1995). Higher amount of $\mathrm{Ni}^{2+}$ can be rapidly taken up and accumulated by the plant root system (Ali et al., 2008). In this work, the highest concentration of $\mathrm{Ni}^{2+}$ taken up by the root of Olea europaea seedlings was $12.697 \mathrm{mg} / \mathrm{kg}$ above the control. Madhava and Sresty (2000) reported that the uptake of $\mathrm{Ni}^{2+}$ by plant was concentration dependent.

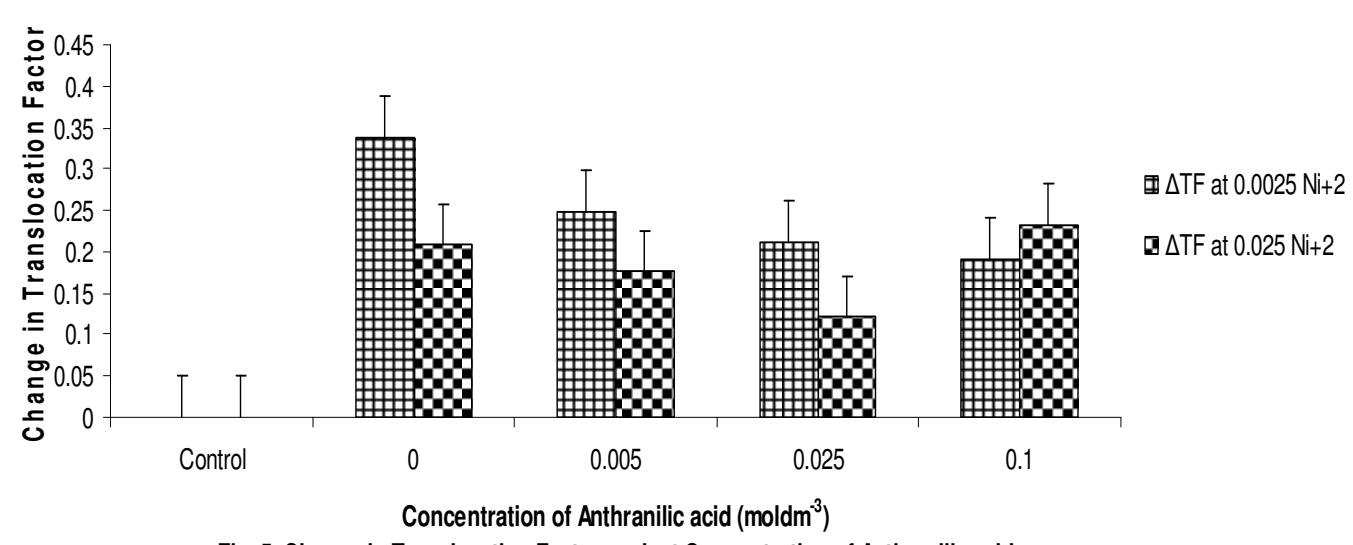

Fig. 5: Change in Translocation Factor against Concentration of Anthranilic acid

\section{Change in Translocation Factor ( $\Delta \mathrm{TF}$ )}

The translocation factor or mobilization ratio was calculated by dividing the concentration of nickel in the shoot with the corresponding root concentration. TF $<1$ and TF $>1$ respectively, at low and high capacity to translocate nickel from the roots to the shoots (Zhang et al, 2000). Fig. 5 shows the changes in $\mathrm{Ni}^{2+}$ translocation factor.
There was a significant change in $\mathrm{Ni}^{2+}$ translocation factor $(\mathrm{Pr}=0.0002<0.05)$. This was determined by subtracting the $\mathrm{Ni}^{2+}$ translocation factor in a particular treatment from the control value. Fig. 5 indicates that the $\mathrm{Ni}^{2+}$ accumulated was largely retained in the roots (TF ratio $<1$ ). This result agrees with the findings of (Hozhina et al., 2001)who reported that protective barriers exist to prevent the penetration of $\mathrm{Ni}^{2+}$ from the roots to the shoots. The high $\mathrm{Ni}^{2+}$ concentrations would cause weak plant growth, leading to depression, metabolic disorders and chlorosis (Kabala et al, 2008).

\section{CONCLUSION}

The effects of anthranilic acid on $\mathrm{Ni}^{2+}$ absorption by olive seedlings replanted in hydroponic solutions was studied. It was found that addition of 0.000 to $0.025 \mathrm{moldm}^{-3} \mathrm{Ni}^{2+}$ and 0.000 to 0.100 moldm $^{-3}$ anthranilic acid to various hydroponic solutions affected the growth of replanted olive (Olea europaea) seedlings. Seedlings grown in treated solutions died earlier than those grown in control. The weights of harvested plants decreased due to the phytotoxic effects of nickel. The rate and extent of translocation of nickel within the plants depended on the concentrations of $\mathrm{Ni}^{2+}$ and anthranilic acid in the hydroponic mixtures. The highest concentration of nickel taken up by the root was $12.697 \mathrm{mg} / \mathrm{kg}$ above the control. This was given by the seedling grown in a solution treated with $0.025 \mathrm{moldm}^{-3}$ of $\mathrm{Ni}^{2+}$ and 0.100 moldm $^{-3}$ anthranilic acid. The TF ratio for all seedlings was less than 1.00 which indicated that the $\mathrm{Ni}^{2+}$ accumulated was largely retained in the roots. This could be used in phytoremediation technique to remove $\mathrm{Ni}^{2+}$ pollutants from the environment or to decrease their toxicity. The technique has many advantages which include low economic costs and the possibility of being applied to soils, causing a minimum environmental impact.

\section{Acknowledgement}

The authors are very grateful to Prof. Sunusi Muhammad Gaya of Department of Agronomy, Mr. Joseph Ejembi and Abubakar Khalil of the Department of Pure and Industrial Chemistry, Bayero University, Kano for their invaluable contributions to the success of this research. 


\section{REFERENCES}

Ali B, Hayat S, Fariduddin Q, Ahmad A, (2008). Epibrassinolide protection against the stress generated by salinity and nickel in Brassica juncea. Chemosphere, 72: 1387-1392.

Baccouch S, Chaoui A, El Ferjani E (2001). Nickel toxicity induces oxidative damage in Zea mays roots. J Plant Nutr 24: 1085-1097

Brune A, Dietz KJ. (1995). A comparative analysis of elements composition of roots and leaves of barley seedlings grown in the presence of toxic cadmium, molybdenum, nickel, and zinc concentrations, Journal of Plant Nutrient 18: 853-868.

Hozhina E. I., Khramov A. A., Gerasimov P. A., Kumarkov A. A. ( 2001). Uptake of heavy metals, arsenic and antimony by aquatic plants in the vicinity of ore mining and processing industries, Journal of Geochemical Exploration, 74: 153- 162.

IITA (International institute of Tropical Agriculture).(1979): Laboratory Manual on Basic Soil and Plant Analyses, 3rd edition, Longman London, UK, 9-67.

Kabala K M, Janicka-Russak M, Burzynski M, Klobus G,( 2008). Comparison of heavy metal effects on the proton pumps of plasma membrane and tonoplast in cucumber root cells, Journal of Plant Physiology, 165: 278-288.

Kazemi N., Khavari-Nejad R. A., Fahimi H., Saadatmand S., Nejad-Sattari T. (2010). Effects of exogenous salicylic acid and nitric oxide on lipid peroxidation and antioxidant enzyme activities in leaves of Brassica napus $L$. under nickel strees, Sci Hort 126: 402-407

Kupper H, Kroneck PMH (2007). Nickel in the environment and its role in the metabolism of plants and cyanobacteria, In: Sigel A, Sigel $H$, Sigel RKO (eds) , Metal lons in Life Sciences, Vol 2, Wiley, New York, USA, Pp 31-62.

Madhava R. K. V., Sresty T. V. S., (2000).Antioxidative parameters in the seedlings of pigeon pea (Cajanus cajan (L.) Millspaugh) in response to $\mathrm{Zn}$ and Ni stresses, Plant Science, 157: 113128.

Pandey N, Sharma CP (2002). Effect of heavy metal ions $\mathrm{Co}^{2+}, \mathrm{Ni}^{2+}$ and $\mathrm{Cd}^{2+}$ on growth and metabolism of cabbage, Plant Sci ,163: 753-758

Peralta J.R, Gardea-Torresdey J. L, Tiemann K.J., Gomez E., Arteaga S., Rascon E. and Parsons J. G. (2000).Study of the Effects of Heavy Metals on Seed Germination and Plant Growth on Alfalfa Plant (Medicago sativa) Grown in Solid Media, Proceedings of the 2000 Conference on Hazardous Waste Research, 135-139.

Sharma S S and Gaur J P, (1995). Potential of Lemna polyrrhiza for removal of heavy metals, Ecological Engineering, 4: 3743.

Wang SH, Zhang $\mathrm{H}$, Jiang SJ, Zhang L, He QY, He HQ (2010). Effects of the nitric oxide donor on antioxidant enzymes in wheat seedling roots under nickel stress, Russ J Plant Physiol 57: 833-839

Zhang WH, Cai Y, Tu C, Ma LQ(2000). Arsenic speciation and distribution in an arsenic hyperaccumulating plant, Sci Total Environ, 300:167-77. 